\title{
Postmyocardial infarction syndrome
}

Sir,

We have read with interest the article by Welin et al. (1983; 50: 140-5) regarding the postmyocardial infarction (Dressler's) syndrome. The authors reported 60 cases of postmyocardial infarction syndrome in 1809 cases of myocardial infarction in a 10 year period (1968-77). This study makes an interesting comparison with a more recent investigation by Lichstein et al. ${ }^{1}$ who suggested that Dressler's syndrome had decreased in incidence and perhaps disappeared. They considered that the decreased use of oral anticoagulants in their unit and more aggressive treatment of postmyocardial infarction pericarditis were responsible for their findings. Dressler ${ }^{2}$ himself postulated that anticoagulants may be implicated in the genesis of the postmyocardial infarction syndrome by causing leakage of blood into serous cavities and thereafter a pericarditis. We would be interested to know whether anticoagulants were given to the patients in Welin's group, and if so whether cases of postmyocardial infarction syndrome occurred more frequently in these patients. Perhaps in the 10 years of the study their anticoagulation policy changed. It would be relevant to know whether the prevalence of Dressler's syndrome paralleled this change.

In addition, the authors make no mention of the prevalence of early postmyocardial infarction pericarditis in their group. As suggested by Lichstein et al. , ${ }^{1}$ perhaps aggressive treatment of this phenomenon may modify the prevalence of Dressler's syndrome. Did any of Welin's group develop early postmyocardial infarction pericarditis, and if so did any of these cases evolve into Dressler's syndrome? The incidence of early postmyocardial infarction pericarditis is $6.8 \%$ to $16 \%^{34}$; some workers feel that patients who develop Dressler's syndrome have all had early postmyocardial infarction pericarditis. ${ }^{5}$ If this is the case, then aggressive treatment of early postmyocardial infarction pericarditis may reduce the prevalence of Dressler's syndrome. Is there any information from Welin's group regarding such treatment?

Robin J Northcote, J B McGuinness, Division of Clinical Medicine,

Victoria Infirmary,

Glasgow.

\section{References}

1 Lichstein E, Arsura E, Hollander G, Greengart A, Sanders $M$. Current incidence of postmyocardial infarction (Dressler's) syndrome. Am f Cardiol 1982; 50: 1269-71.

2 Dressler $W$. The post-myocardial infarction syndrome. Arch Intern Med 1959; 103: 28-42.
3 Thadani U, Chopra MP, Aber CP, Portal RW. Pericarditis after acute myocardial infarction. $\mathrm{Br} \mathrm{Med} \mathcal{F}$ 1971; ii: 135-7.

4 Khan AH. Pericarditis of myocardial infarction: review of the literature with case presentation. Am Heart $\mathcal{F}$ 1975; 90: 788-94.

5 Kossowsky WA, Lyon AF, Spain DM. Reappraisal of the post-myocardial infarction Dressler's syndrome. $\mathrm{Am}$ Heart f 1981; 102: 954-6.

Sir,

Welin and colleagues (1983; 50: 140-5) have nicely reported their experiences with the postmyocardial infarction syndrome. We discharge about 350 patients a year with proved myocardial infarctions and rarely, if ever, are sure of detecting that syndrome. (We do not, however, have the powerful tool that Welin and colleagues have-a formal follow up clinic-and, therefore, such impressions are not as well founded.) The authors did not include data on a demonstrable pericardial component of their patients' syndromethat is, pericardial rubs with or without typical (stage I) ST segment changes on the electrocardiogram. It would be of interest to know how many of their patients had had a pericardial rub during their admission to hospital for acute infarction ("epistenocardiac pericarditis"), how many had had pleuritic chest pain at that time, and how many had a rub with their postmyocardial infarction syndrome.

David H Spodick,

Cardiology Division,

University of Massachusetts Medical School,

St Vincent Hospital,

Worcester,

Massachusetts,

USA.

These letters were shown to the authors, Dr Welin and colleagues, who reply as follows:

Sir,

We are delighted that our report on the postmyocardial infarction syndrome (1983; 50: 140-5) has met with interest, and we provide the following answers to the questions raised.

With respect to anticoagulants, it has been the policy (also carried out before the present series of patients) to give anticoagulants orally for one week or less to all patients with suspected or confirmed myocardial infarction while in hospital until they are ambulant. This policy has not been changed.

Of the 60 patients with the postmyocardial infarc- 
tion syndrome, 14 ( $23 \%)$ had a confirmed early postmyocardial infarction pericarditis. In a previous study from our group of $\mathbf{3 0 0}$ men with a first infarction, early postmyocardial infarction pericarditis was reported among 21 (7\%) men. Of our 1809 patients the prevalence of early postmyocardial infarction pericarditis is not known since many observers reported the data, which led to wide interobserver variations. Thus we do not know how many patients with early postmyocardial infarction pericarditis later developed the postmyocardial infarction syndrome.

There has been no rigid policy for treating eariy postmyocardial infarction pericarditis. In patients with pain non-steroidal anti-inflammatory drugs are given, and if these do not control the pain we give steroids.

With regard to Dr Spodick's questions, all confirmed cases of early postmyocardial infarction pericarditis had a pericardial rub (see above), and 42 (70\%) patients had pleuropericardial chest pain. Rubs were noted in the records of $34(57 \%)$ patients. This is most probably an underestimate of the true prevalence since many rubs are of short duration, sometimes lasting only a few hours.

Lennart Welin, Anders Vedin, Claes Wilhelmsson, Department of Medicine,

Östra Hospital,

S-416 85 Göteborg,

Sweden.

\section{Notices}

\section{European Society for Clinical Investigation}

The eighteenth annual meeting of the society is to be held on 17-19 April 1984 in Milan, Italy. Further information may be obtained from: Fondazione Giovanni Lorenzini, Via Monte Napoleone 23, Milan 20121, Italy.

\section{Antwerp-La Jolla Research Conference on Cardiac Function}

An international meeting will be held on 2-4 July 1984 in Antwerp, Belgium. The subject of the conference is "Non-uniformity of contraction and relaxation." Further information may be obtained from: $\mathrm{Dr}$ D L Brutsaert, Department of Physiology and Medicine, University of Antwerp, Groenenborglaan 171, 2020 Antwerp, Belgium.

\section{British Cardiac Society}

The Annual General Meeting for 1984 will take place in Leicester on 11 and 12 April 1984, and the closing date for receipt of abstracts is 3 January 1984 .

The Autumn Meeting in 1984 will be held on 3 and 4 December 1984, and the closing date for receipt of abstracts will be 15 August 1984 . 